\title{
Graduate Courses in Occupational Therapy and International Classification of Functioning, Disability and Health
}

\author{
Ana Rita Costa de Souza Lobo Braga, Leonardo Petrus da Silva Paz, \\ Vera Regina Fernandes da Silva Marães \\ University of Brasília, Brasília, Brasil \\ Email: veraregina@unb.br, vrmaraes@gmail.com
}

Received 25 August 2015; accepted 24 October 2015; published 27 October 2015

Copyright (C) 2015 by authors and Scientific Research Publishing Inc.

This work is licensed under the Creative Commons Attribution International License (CC BY). http://creativecommons.org/licenses/by/4.0/

(c) () D Den Access

\section{Abstract}

The formation of Occupational Therapists has become the subject of analysis and debate in recent decades after several changes in health policies in Brazil, among them the implementation of the National Curriculum Guidelines (NCGs) directing teaching practices in line with the Health Unic System and International Classification of Functioning, Disability and Health (ICF). Given these paradigms, the Occupational Therapy courses passed with several adjustments in their course of pedagogical political projects (PPPs) and their teaching practices. The study's goal was to characterize the Occupational Therapy courses and analyze their PPPs focusing on changes in the health care model and the inclusion of ICF. The research was exploratory and was conducted through documentary analysis. By 2013 there were 63 occupational therapy courses working in the country, 44 in private institutions and 19 in public, demonstrating a lack of supply in public. The Occupational Therapy courses are still guided by the biomedical model, and the applicability of the ICF as well as the insertion of the biopsychosocial model are incipient in teaching practice.

\section{Keywords}

International Classification of Functioning, Disability and Health, Education, Occupational Therapy, Functioning, Biopsychosocial Model

\section{Introduction}

The training of health professionals has become the subject of analysis and debate in recent decades after several changes in health policies in Brazil, and there is thus a need to assess the impact of these changes in scientific 
and technological areas, social and political country and responding to the needs of Brazilian society. Driven by the negative evaluation processes of higher education and existing curricula, the need for curriculum change (Pinto \& Yokoyama, 2008). Given this situation, education involves reformulation of the National Curriculum Guidelines (NCGs) for health courses, approved mostly between 2001 and 2002. The new NCGs seek to integrate education with health and point to the need of the courses incorporate into their projects teaching the theoretical framework of the Unified Health System (UHS) in order to promote quality higher education and enter the reality of public services to the practices of graduate courses from the first year.

Alongside these changes in the health policies of Brazil, in 2001 the World Health Organization (WHO) has developed the International Classification of Functioning, Disability and Health—ICF, in order to standardize and unify health language worldwide, providing a conceptual basis for the definition, measurement and policy formulations for health and disability. It is a universal classification of disability and health for use in health and health-related sectors (OMS, 2003). From then ICF was recommended and widespread in all WHO member countries, in order to turn into universal information data on health, complementing the International Classification of Diseases (ICD). The use of ICD in conjunction with the ICF facilitates the survey, consolidation, analysis and interpretation of data and information for national consistent on health grounds. The use of two WHO classifications can facilitate the comparison of the health information about populations over time, among countries and regions (Farias \& Buchalla, 2005). The focus of the "new" classification is the transformation of the approach based on the disease to emphasize the functional model as a health component, proposing the implementation of the biopsychosocial approach. To Sampaio and Luv (2009), the model proposed by the ICF is used to obtain an integration of the various dimensions of health (biological, individual and social).

In 2003, the ICF was translated into Portuguese and presented in Brazil and in 2009 the Federal Council of Physical Therapy and Occupational Therapy (COFFITO) recommended the use of ICF by the physiotherapist and occupational therapist within their respective institutional, according to Resolution No. 370/2009. Following the global trend, on May 10, 2012, the Ministry of Health established the use of ICF in the Unified Health System, including the Health Insurance, through Resolution No. 452/2012. Faced with this panorama, the undergraduate courses in Occupational Therapy, reshaped over the years their pedagogical political projects to meet the new recommendations, however, it appears that higher education in Occupational Therapy has not incorporated in most undergraduate courses, the proposal health model of WHO and the implementation of the ICF. The objective of the study was to characterize the Occupational Therapy courses and analyze their pedagogical projects focused on the paradigm shift in the health care model and the inclusion of the International Classification of Functioning, Disability and Health-ICF.

\section{Methodology}

The research was exploratory feature and was conducted through desk review with appreciation of contemporary or retrospective documents, considered scientifically authentic.

It was conducted survey of undergraduate courses in Occupational Therapy in activity in the country through the system of the Ministry of Education (e-MEC) and then checked the total workload, time of payment and the type of high education institutions where they were offered (public or private university or college). After the lifting of such information, the pedagogical projects of the courses were selected, (PPPs) built or revised between 2003 and 2013 and which were available on the pages of IES or search engine.

Then these PPPs were analyzed to verify that the ICF would be contemplated in its content and/or the menus and basic and complementary references disciplines.

For qualitative analysis, a search is performed of the contents of PPPs in order to verify the use of ICF as a statistical tool for research and clinical tool, social policy and teaching tool, moreover, it was examined the evidence for the use of biopsychossocial model in undergraduate courses in Occupational Therapy. For quantitative analysis, data were represented as the frequency of events, and was carried out analysis of means and percentages of occurrence of the events.

\section{Results}

Research on the e-MEC pointed 73 undergraduate degrees in Occupational Therapy in private and public higher education institutions, among those 63 remain in operation, five in the process of extinction and the other five are extinct. Whereas a degree in occupational therapy in Brazil can be offered in high education institutions 
Federal and private, it turns out that the courses offered in private higher education institutions account for more than twice the free universities, 19 Public; among them three state and 16 federal. Count up 44 private universities distributed in the country, and of these, 23 are colleges and 21 universities are.

With regard to regions in which courses are offered, Brazil's Southeast has the highest concentration contemplating 34 courses, followed by the Northeast with twelve courses, the South with eight courses, the North with six and the Midwest with three offered courses.

The study showed that of the 63 courses, only 20 PPPs were located the sites of Education Institutions or research site. Of those, only eight courses contemplating the ICF in the PPP content, descriptions of their menus on their basic references or references complementary disciplines. The use of ICF, it was found that among the eight courses, ICF is only used as a clinical tool in three courses and as a teaching tool in a course. No evidence was found of the use of ICF as a statistical tool, research and social policy.

To be considered as courses that follow the biopsychosocial model, characteristic of the ICF, the PPP would have to deal with the three areas: biological, individual and social. Thus, after analysis of 20 PPPs available for research in seven of the biopsychosocial model is evidenced, for contemplate all three axis (Table 1).

\section{Discussion}

The need for change in the education of health professionals is internationally recognized, given the inadequacy of the educational institutions to respond to social demands. Institutions are encouraged to turn in the direction of a school that, among other attributes, values equity and the quality of care and efficiency and relevance of health work (Cyrino \& Toralles-Pereira, 2004). Among the challenges of this process of change, it is difficult to

Table 1. Biopsychosocial model (ICF) in graduate courses in occupational therapy.

\begin{tabular}{|c|c|c|c|}
\hline Courses & BIOLOGICAL FACTORES & INDIVIDUAL FACTORES & SOCIAL FACTORES \\
\hline C11 & YES & NO & YES \\
\hline $\mathrm{C} 20$ & YES & YES & YES \\
\hline $\mathrm{C} 21$ & YES & YES & YES \\
\hline $\mathrm{C} 26$ & YES & NO & YES \\
\hline $\mathrm{C} 27$ & YES & YES & YES \\
\hline $\mathrm{C} 28$ & YES & NO & YES \\
\hline C29 & YES & YES & YES \\
\hline С30 & YES & YES & YES \\
\hline C35 & YES & NO & YES \\
\hline С36 & YES & NO & YES \\
\hline C37 & YES & NO & YES \\
\hline С38 & YES & NO & YES \\
\hline С39 & YES & YES & YES \\
\hline $\mathrm{C} 40$ & YES & NO & YES \\
\hline $\mathrm{C} 41$ & YES & NO & YES \\
\hline $\mathrm{C} 47$ & YES & NO & YES \\
\hline C50 & YES & NO & YES \\
\hline C54 & YES & NO & YES \\
\hline $\mathrm{C} 60$ & YES & YES & YES \\
\hline C62 & YES & NO & YES \\
\hline
\end{tabular}

Fonte: PPPs found on search sites. 
break away from traditional teaching models and the information transmission approach to prepare students with skills to deal with human relations in health care (Barba et al, 2012).

An interesting factor identified in this study indicates that the largest number of occupational therapy courses, 69.85\% are in private universities and $30.15 \%$ in public, which corroborates with the study of Haddad et al. (2009) describing that higher education in Brazil is predominantly private (between $70 \%$ and $80 \%$ ). On the other hand, in other countries in the 90's it was observed that the USA had 8,519,457 undergraduate students, with $72.4 \%$ of them studying at public universities. France had 2,150,000 students, 92.2\% attending public schools; England had 822,000 students, $99.9 \%$ in schools funded by the state. Argentina, with 677,000 students, $90 \%$ had them in public schools. However, Brazil, with 1,661,034 students, offered only $41.6 \%$ of the vacancies in public schools (21.9\% Federal, 14\% State and Municipal 5.7\%) (Vaidergorn, 2001).

According to Haddad et al. (2009), between 1991 and 2008 there was an increase of 458\% in the number of courses in the health field in Higher Education Institutions both public and private, stimulated by the expansionist policy of the government. In research carried out by Lopes et al. (2010) between the years 2008 and 2010 there was an expansion of undergraduate education in Occupational Therapy in Higher Education Institutions, especially in public universities linked to Restructuring and Expansion of Federal Universities program, which created undergraduate courses in different parts of the country in order to balance the number of the distribution of these in all regions, however, the data from this study show that this fact is not yet a reality. The publication of national curriculum frameworks of bachelor's Ministry of Education (2010) reveals that the Brazilian higher education is in singular situation: need to expand as social demand, but has a disproportionate distribution offering, whose expansion may compromise its social function. The disproportionality of supply manifests itself in two ways: a large concentration of vacancies in a few courses, with consequent deficiency in the others, and extreme spraying of courses across the country, making it difficult to identify training profiles attuned to the social and economic reality.

Haddad et al. (2009) warns that the increase in courses in health may have reconfigured the undergraduate education and the labor market by bringing an imbalance between supply and demand, determined by regional differences for both the opening of places for training as the posts of work. Also points to the fact that demographic and epidemiological reality is changing and with it changing population needs and demands for health care. This alert corroborates data found in this research, since 53\% of Occupational Therapy courses are concentrated in the Southeast, between the states of São Paulo, Rio de Janeiro and Minas Gerais. The fewer courses are in the Midwest. The concentration of courses in the Southeast and the small number of courses offered in the Midwest can be justified by the difference in the number of inhabitants in the regions. According to statistics from the Brazilian Institute of Geography and Statistics (BIGS), the Central West region has around 14 million inhabitants and is the least populated of the country and the Southeast region has a population accounted for about 80 million people, considered the most populous. Dialoguing with the data found and the ICF the study by Ruaro et al. (2012) on the outlook and the profile of the use of ICF in Brazil, it reveals the fact that most research on the ICF focuses in Southeastern Brazil, coinciding indeed with the largest number of institutions. In studies related to public and private institutions, Silva (2001) points out that public higher education is successfully developing in postgraduate and research but the graduate vacancies in addition to poor regional distribution does not meet the demand of society for places in undergraduate education.

Regarding the application of ICF in PPPs, and therefore the training of professionals, research shows that the courses include the WHO classification are only seven, whereas this analysis was carried out in the universe 20 PPPs available, so 35\% PPPs adhere to the use of the ICF in its content. Although it seems very little, this data follows a global trend the survey Wiegand et al. (2012) indicating a growth of publications on the ICF between the years 2001 and 2010, especially regarding the use of the classification in clinical settings rehabilitation. The greater number of publications in these contexts is according to this study shows that the extent that ICF, as contemplated in occupational therapy courses is used as a clinical tool.

Another factor that contributes to the scarcity of ICF practice and can also justify the inclusion of this classification within PPPs, is the difficulty in application due to its complexity and the form of the code organization. The limitations on the applicability of ICF by health professionals is a point highlighted in research, such as Sabino et al., 2008, showing the difficulty of codes selection among the large existing amount and the possibility of using more than one code to classify some categories of components activities/participation, are limiting factors for the use of ICF.

According to these facts, a survey conducted in Spain by Reed et al. (2008) also points out the difficulty in 
teaching the ICF in undergraduate courses and, can also, shows that there is a lack of systematic descriptions in the literature about the best ways to teach health professionals and students to use such a classification. That study reports that the training of the use of ICF for students of occupational therapy are effective both in instructor with learning format in the classroom and in the self-directed format, however, the class format proved to be more significant in terms of learning the skill the actual coding.

In a study on the standardization of evaluations of physiotherapy students in clinical practice, Andrade (2010) lists the competencies and skills established by NCG of undergraduate courses in Physical Therapy and the ICF categories. The result shows that the link between the ICF and the NCG provides the foundation to guide the academic review content as per the requirements of the Ministry of Education and the biopsychosocial approach advocated by WHO. Still on studies at graduation, Jelsma and Scott (2011), pointed out that the ICF increases the clinical reasoning of scholars to demonstrate the links between activity limitations and participation restrictions, in addition to analyzing the problems of individuals relating them to factors environmental and personal factors. Once this has been achieved, students are able to plan appropriate treatment interventions in order to consider the individual as a whole, like, biopsychosocial manner.

The biopsychosocial approach seeks to integrate the sociological research with biological science as a basis for developing a relational understanding of the body. In the specific case of human functionality, this approach rejects the attempted separation of biological, social and psychological components (Imrie, 2004).

The ICF proposes the operationalization of the biopsychosocial approach by adopting a multidimensional model of functioning and disability, however, according to data disclosed in this study, this fact is not yet a common practice in undergraduate courses in Occupational Therapy, although the profession is defined the World Federation of Occupational Therapists (WFOT) as "a field of knowledge and intervention in health, education and social sphere, gathering technologies aimed at emancipation and autonomy of people who, for reasons linked to specific problems, physical, sensory, mental, psychological and/or social, have temporarily or permanently, difficulty in integration and participation in social life” (Baridoti et al., 2002).

To Ceccim and Feuerwerker (2004), the adoption of NCG was an attempt to break with the paradigm biologicist, medicalized and hospital procedure-centered still hegemonic, to meet the new challenges of the contemporary world, knowledge production and production occupations; however, it is not the current reality. This information confirmed by research Andrade (2010) on the biopsychosocial model on academic probation when highlights the need to break the paradigm of traditional biomedical during the training process.

\section{Conclusion}

Considering the information obtained in the results, this study indicates that despite the establishment of NCGs in 2002 recommending that the occupational therapist has a generalist training; and the recommendations of COFFITO, to include the ICF in professional practice, WHO and currently UHS for the implementation of the biopsychosocial health of the ICF model in the country, this study shows that it is still scarce of the applicability of this new concept in health to guide the training of professionals in Occupational Therapy.

So that the ICF and the biopsychosocial model are performed by occupational therapists, it is necessary for undergraduate submit proposals equivalent to the new ICF health model in the educational process through teaching this classification in practice the students in the classroom, in teaching laboratories and in stages. The study results suggest that there are features recommended by NCGs in PPPs, however, most of these documents still have the biomedical profile in training in Occupational Therapy. The cut made by this study, based on analysis of PPPs does not exhaust the subject of these research possibilities.

There is an evident need for investigative and guiding studies on the teaching of the ICF and the paradigm shift in the healthcare model, with a greater number of courses, taking into account the different perceptions of stakeholders in the subject as teachers and researchers. However, this study may contribute to the improvement of the curriculum of undergraduate courses in Occupational Therapy, as it points to a shortage of viewing the inclusion of the ICF graduate of Occupational Therapy, as well as the biopsychosocial model. To take effect the recommendations of NCGs (2002), the COFFITO (2009), WHO (2003) and UHS (2012), to insert the ICF undergraduate and health services, it is necessary to rethink the ways of structuring the processes of formation of the professionals of today and the future content changes strategies should be incorporated practices of learning scenarios and stages Services. It is concluded that the characterization of the quality of teaching, and consequently the actions in health services depends on not only the technological advances, but also the transmission of relevant data at the undergraduate and building the skills and professional skills. Therefore, it is important that PPPs 
are updated and teachers incorporate active measures and transformative teaching methodologies.

\section{References}

Andrade, P. M. O. (2010). Physiotherapy Stage Evaluation According to Curriculum Guidelines and the Biopsychosocial Perspective of the World Health Organization. Magazine Higher Education Evaluation, Vol. 15, Campinas, Sorocaba, São Paulo.

Barba, P. C. S. D., Silva, R. F., Joaquim, R. H. V. T., \& Brito, C. M. D. (2012). Innovative Training in Occupational Therapy. Magazine Interface, Vol. 16, No. 42, Botucatu, São Paulo.

Baridoti, E. A., Barro, D. R. P., Pereira, M. B., \& Sant’Anna, M. M. M. (2002). Occupational Therapy Settings. São Paulo: Colleges Salesianas de Lins, WFOT.

Ceccim, R. B., \& Feuerwerker, L. C. M. (2004). Change in Graduate Professions in Health in the Integral Shaft. Reports in Public Health, Vol. 20, Rio de Janeiro.

Cyrino, E. G., \& Toratelles-Pereira, M. L. (2004). Working with Teaching and Learning Strategies for Discovery in Health Care: The Questioning and Problem-Based Learning. Reports in Public Health, Rio de Janeiro.

Farias, N., \& Buchalla, C. M. (2005). The International Classification of Disability and Health of the World Health Organization: Concepts, Uses and Perspectives of Brazilian Epidemiologia, São Paulo.

Haddad, A. E., Morita, M. C., Pierantoni, C. R., Brenelli, S. L., Passarella, T., \& Campos, F. E. (2009). Training of Health Professionals in Brazil: An Analysis from 1991 to 2008. Journal of Public Health, Brasília.

Imrie, R. (2004). Demystifying Disability: A Review of the International Classification of Functioning, Disability and Health. Sociology of Health \& Illness, 26, 287-305. http://dx.doi.org/10.1111/j.1467-9566.2004.00391.x

Jelsma, J., \& Scott, D. (2011). Impact of Using the ICF Framework as an Assessment Tool for Students in Pediatric Physiotherapy: A Preliminar Study. Physiotherapy, 97, 47-54. http://dx.doi.org/10.1016/j.physio.2010.09.004

Lopes, R. E., Malfitano, A. P. S., Oliver, C. F., Sfair, S. C., \& Medeiros, T. J. (2010). Research in Occupational Therapy: Notes about the Academic Paths on the National Scene (Vol. 21, pp. 207-214). Magazine Occupational Therapy, São Paulo: University de São Paulo.

OMS (2003). International Classification of Functioning, Disability and Health. São Paulo: World Health Organization.

Pinto, S. C. A., \& Yokoyama, A. Y. (2008). Integrated Curriculum in the Formation of Occupational Therapist for the National Health System: The Collective Pedagogical Project (Vol. 32, pp. 51-60). Bahia Journal of Public Health, Salvador.

Reed, G. M., Dilfer, K., Bufka, L. F., Cherer, M. J., Kotze, P., Tshivhase, M., \& Stark, S. L. (2008). Three Model Curricula for Teaching Clinicians to Use the ICF. Disability and Rehabilitation, 30, 927-941. http://dx.doi.org/10.1080/09638280701800301

Ruaro, J. A., Ruaro, M. B., Souza, D. E., Frez, A. R., \& Guerra, R. O. (2012). Panorama Profile and the Use of ICF in Brazil -A Decade of History. Brazilian Journal of Physical Therapy, 16, No. 88.

Sabino, G. S., Coelho, C. M., \& Sampaio, R. F. (2008). Using the International Classification of Functioning, Disability and Health in the Physical Therapy Assessment of Individuals with Musculoskeletal Disorders of the Lower Extremities and Lower Back. Acta Fisiátrica, 15, No. 1.

Sampaio, R. F., \& Luz, M. T. (2009). Human Functioning and Disability: Exploring the Scope of the International World Health Organization Classification. Cadernos de Saúde Pública, 25, 475-483.

Silva, A. C. (2001). Some Problems of Our Higher Education. Advanced Studies USP, 15, No. 42.

Vaidergorn, J. (2001). A Perspective of Globalization in Brazilian Universities. Cadernos CEDES, 21, 78-91.

Wiegand, N. M., Belting, J., Fekete, C., Gutenbrunner, C., \& Reinhardt, J. D. (2012). All Talk, No Action? The Global Diffusion and Clinical Implementation of the International Classification of Functioning, Disability, and Health. American Journal of Physical Medicine \& Rehabilitation, 91, 550-560. 